\title{
MAKING COMMUNITY-BASED TOURISM SUSTAINABLE: EVIDENCE FROM THE FREE STATE PROVINCE, SOUTH AFRICA
}

\author{
Albert J. STRYDOM \\ Central University of Technology, Faculty of Management Sciences, \\ Park Road, Bloemfontein, South Africa, e-mail: astrydom@cut.ac.za \\ Dinah MANGOPE \\ Central University of Technology, Faculty of Management Sciences, \\ Park Road, Bloemfontein, South Africa, e-mail: mangope23@yahoo.com
}

\begin{abstract}
Unathi Sonwabile HENAMA*
Tshwane University of Technology, Department of Tourism Management, Faculty of Management Sciences, Staatsartilleries Road, Pretoria, South Africa, e-mail: HenamaUS@tut.ac.za
\end{abstract}

Citation: Strydom, A.J., Mangope, D., \& Henama, U.S. (2019). MAKING COMMUNITY-BASED TOURISM SUSTAINABLE: EVIDENCE FROM THE FREE STATE PROVINCE, SOUTH AFRICA. GeoJournal of Tourism and Geosites, 24(1), 7-18. https://doi.org/10.30892/gtg.24101-338

\begin{abstract}
Community-based tourism (CBT) has been promoted as a way of development whereby the socio-cultural, environmental and economic needs of local communities are met through tourism product offerings. CBT is concerned with ensuring that the local community benefits directly from the tourism industry. CBT is known to contribute to social and economic survival of the marginalised communities in developing countries and the preservation of natural resources in the affected areas. In developing countries, tourism has often been observed as the spin around for small-scale enterprises and job creation, and therefore the uplifting of local communities' standard of living. Where CBT is practiced well, there is a potential to provide some exceptional opportunities for communities by offering not only better benefits, but also enhancing their contribution in planning and management of tourism in their communities. The primary goal of the study was to investigate the sustainability of financial investment in community-based tourism projects in the Thabo Mofutsanyana Municipality. Secondary objectives were set, namely: to determine if the projects can sustain themselves after funding support has been terminated, to determine the oversight role played by government on how funding has been utilised, and to formulate guidelines on how to increase the sustainability of CBT projects. CBT projects have the potential of opening up avenues for locals and economically deprived communities to have a meaningful contribution in tourism. The qualitative study sought to investigate the sustainability of financial investments in CBT within the Thabo Mofutsanyane area. The results indicated that financial investments are important for CBT. Financial investments are not an end, as marketing planning and skills development can ensure the success of CBT. This article offers developing destinations will critical
\end{abstract}

\footnotetext{
* Corresponding author
} 
success factors for CBT projects that are used to create a tourism supply chain for residents and citizens of a tourism destination.

Keywords: South Africa, tourism, community-based tourism, Thabo Mofutsanyana, Quality-of-Life

\section{INTRODUCTION}

The African National Congress (ANC) government elected in 1994 elections adopted the Reconstruction and Development Plan (RDP) as a programme of action to arrest poverty, unemployment and inequality. Tourism was later identified as an engine for growth for the economy as the traditional sectors such as mining and agriculture had a declining share in employment and contribution to the gross domestic product (GDP) (Henama, 2014). Tourism is premised on the sharing of the developmental benefits of tourism with economically challenged members of society and their respective communities. South Africa has a high rate of unemployment, which is a leading contributor towards poverty, a growth trap within the economy and a skills mismatch, which keeps millions of South Africans outside of formal employment.

Tourism destinations attract tourists because of the positive economic impacts such as labour-intensive jobs, tourism acting as a catalyst for other industries. Tourism attracts foreign exchange, and foreign direct investment that comes with tourism and simulates small businesses (Acha-Anyi et al., 2016). According to Henama (2017) tourism has been an economic messiah for South Africa, as perennial job losses have resulted in the increase of poverty. The high rate of unemployment in South Africa, has resulted in unemployment being a structural issue facing the economy. The decline of jobs in mining, has been mitigated by the growth of jobs in the tourism industry.

The tourism industry has more employees that the mining industry. This reflects a change in the economic dynamics of the South African economy, changing from mining (production economy) towards tourism (experience economy). Tourism has been used by countries as a form of economic diversification, as the economies changes from primary industries to the services economy. Tourism in South Africa can be regarded as the new gold, as the traditional economic drivers of the economy have been gold mining, with deep vertical and forward linkages. Gold mining has declined, and is no longer the main driver of the South African economy, and it has been replaced by tourism.

The decline in mining production has created widespread unemployment and destroyed the economic prospects of the single industry towns, which depended on mining, as the major economic activity. The tourism industry is associated with small and medium enterprises, which provide the majority of services to tourist. The majority of small firms in tourism continue to create a plethora of job opportunities for thousands of South Africans. Rogerson (2018) noted that informality is a distinct facet of tourism economies in the developing world or global South. The informality of the tourism industry is a character of the small business dominance of this industry. This informality means that the tourism industry can create jobs at the lowest possible cost, and create a plethora of job opportunities. The biggest challenge facing the postapartheid government is the lack of jobs, which has relegated millions of South Africa to poverty as a result of unemployment. Tourism is a growth industry because of its sustained growth Henama, Mangope and Strydom (2017:2). The fact is that the tourism experience at the tourist destinations creates opportunities for other domestic 
enterprises to benefit from the tourism and creates backward linkages in other industries such as agriculture. The majority of the value adding of the tourism product offerings, occur at the destination benefitting local tourism supply chains. Tourism can catalyse other industries such as manufacturing and agriculture when the tourism industry is planned to be pro-poor, and benefit the destination area. Tourism has a direct, indirect and induced impact at the destination economy. Consequently, the effects of tourism can be experienced though the economy of a country. The best-known definition of sustainability or sustainable development comes from the World Commission on Environment and Development and is outlined as: forms of progress that meet the needs of the present without compromising the ability of future generations to meet their needs. It is important to acknowledge that sustainability is about more than just looking after our natural environment. It is also about considering the social and economic impact of what we do and how we do it (NC State University, 2010:1). According to Holden and Linnerud (2007:174) sustainable development entails protecting the earth's capacity to support life in all its diversity.

It embraces concerns for environmental protection, social equity, quality of life, cultural diversity and a dynamic, viable economy delivering jobs and prosperity for all. Sustainable tourism requires the entire destination community to recognise the benefits and need for tourism and demonstrate willingness to invest in whatever it takes to make it happen. Tourists are attracted to destinations because of the attractions, and it's important that the attractions are protected, as the resource base that attracts the tourism. Therefore, the principles of sustainability are applied to the tourism industry to protect the resource base for future generations. It is generally accepted that tourists are attracted to tourism destination attractions, and they usually destroy the very same attractions that drew them to the destinations. The resource base for tourism must be protected to sustain the industry for the long term, and use continued tourism revenue as a force for good for a destination country. Sustainable tourism is therefore a business imperative for the long-term sustainability of the tourism industry.

\section{COMMUNITY-BASED TOURISM}

The tourism industry is supposed to improve the host community, if it is to be sustainable. Therefore, community-based tourism is a means to ensure that the tourism industry benefits the locals, improving their standard of living and Quality-of-Life. Tourism should be developed to cater equally well for both the residents' sense of wellbeing and the tourists' needs and expectations. Community-based tourism is considered as a tool that integrates the goals of the general concept of sustainable development. CBT has to fulfil the criterion that makes it economically sensible as well as socially, culturally and ecologically compatible with the communities in which it takes place (Zapata et al., 2011:725). It is of little use to implement CBT projects if they are not sustainable. This implies that the implementation of CBT projects must happen in such a way that communities and/or projects, where initial financial investments take place, must be managed in such a way that the projects can eventually be maintained without the investment support (Tango International, 2009:8).

Although the term CBT is commonly used in South Africa, the definition is contested and means different things to different people. The lack of consensus seems to stem from whether the community owns and/or manages the tourism venture or facilities and whether the focus is on provision of jobs for local people, or on issues of community involvement in decision-making and sustainability of those projects (Ndlovu \& Rogerson, 2004:8). Leballo, as in Ndlovu and Rogerson (2003:125), argued that several authors accept a broad definition of community-based tourism, as that in 
which a number of local people are involved in providing services to tourists and the tourism industry, and which local people have meaningful ownership, power and participation in the various tourism and related enterprises. Gopaul (2006:11) further reiterates that CBT is becoming increasingly popular in developmental cycles worldwide as a means of contributing towards rural development and poverty alleviation.

This is premised on using tourism as a means for sharing the developmental benefits of tourism. The tourism industry does not naturally benefit the destinations and its citizens, unless dedicated steps are instated to ensure its pro-poor. The intention has been to ensure that tourism contributes towards development and growth. In South Africa, CBT projects are supported and funded by the Department of Small Business Development, Department of Tourism, and the Department of Environmental Affairs (DETEA) through their poverty alleviation grants.

This is part of a broader government project to assist previously neglected groups and the poor South African communities, where most of the resources are concentrated (DETEA, 2012:55-57). Communities incur costs when they engage in CBT projects so they too have an interest in knowing how successful such initiatives are before engaging with Non-Governmental Organisations (NGOs) and others to realise the aspiration of CBT. There is evidence that a large majority of international CBT initiatives enjoy little success. Goodwin and Santilli (2009:4-8) reported research by the Rainforest Alliance and Conservation International where two hundred CBT projects across America were reviewed, revealing that many accommodation providers had only $5 \%$ occupancy. They concluded from their review that "the most likely outcome for CBT initiatives is collapsing after funding dries up". The mentioned authors reported that the main causes of collapse were poor market access and poor governance. Access to markets is linked to having a consistent supply of tourism consumers, which would sustain the CBT. This means that CBT initiatives must be commercially viable and operated as commercial entities. There is growing scepticism of the value of CBT in delivering poverty reduction because of the inability of most schemes to achieve their most fundamental goal of directing sustainable and meaningful benefit flows to poor communities.

\section{Theoretical Framework: Community-Based Tourism}

Sustainable CBT aims to reconcile the tensions between the three partners in the development triangle, and maintains the equilibrium in the long-term. It highlights the aims of sustainable CBT, namely: to minimise the environmental and cultural damage, optimise visitor satisfaction and maximise long-term economic growth for the region. Sustainable tourism (ST) is tourism that does not deplete economic, social/cultural and environmental resources. Over the past decades, sustainability has become a focal point for tourism development around the world. Matarrita-Cascantea et al. (2010:9) state that ST is not just about controlling and managing the negative impacts of the industry. ST development aims to benefit local communities, economically and socially, and to raise awareness and support for conservation of the environment.

The concept of CBT emerged in the mid-1990s. CBT is generally small scale and involves interactions between the visitor and host community and is particularly suited to rural and regional areas. It is commonly understood to be managed and owned by the community, for the community. It is a form of 'local tourism' favouring local service providers and suppliers and focused on interpreting and communicating local culture and the environment. CBT can empower local communities, giving them a sense of pride in their natural resources and control over their respective community's development. CBT should not be viewed as an end in itself, but as a means towards empowering poor communities to take control over their land and resources, to tap their potential, and to acquire the skills necessary for their own development. 


\section{Characteristics of community-based tourism}

CBT is premised on the inclusion of local people in the development of the industry. In fact, its characteristics include local control of development, community involvement in planning, equitable flow of benefits, and incorporation of resident values (Koster, 2010:4):

- Local control of development: there are many interest groups and many individuals who hold their own viewpoints, results in challenges to reach consensus. Communities rarely, if ever, speak with one voice.

- Community involvement in planning: current thinking in tourism focuses on interventions that are strategic and based on an open-minded assessment of where impact can be created at that scale. The other issue is for the government to provide a conducive environment for the private sector to work at any point in the tourism value chain, wherever there is greatest potential for pro-poor change and be able to evaluate the potential environmental, cultural, and social impacts of the intervention and the type of enterprise being developed. This should be done during the planning stage and in participation with local stakeholders to ensure the overall impacts will be beneficial (Spenceley et al., 2009:33). There is a range of ways that pro-poor interventions can be scaled up. These include joint venture partnerships, value chain linkages, community capacity building and skills training (Bricker et al., 2012:104).

- Equitable flow of benefits: according to Höckett (2009:2), rural communitybased tourism proceeds rarely as an unplanned intervention of a free market process but more as a planned programme that is part of local or regional development strategies. This makes it possible to plan community-based tourism development carefully. The communities should discuss what they are willing to contribute and what they are not willing to give up (Hashimoto \& Telfer, 2006:42-45).

- Incorporation of resident values: an important consideration needs to be raised when discussing the relevance of CBT in the development of rural areas. That consideration is the definition and importance of CBT, in the countryside or in a small rural settlement, and that it is made up of ecological elements of tourism (ecotourism), and cultural and traditional tourism. They may include commercial farms, small settlements, rural areas, and other areas further from the towns and cities (Essex et al., 2005:128).

Goodwin and Santilli (2009:27-28) as well as the Asian-Pacific Economic Cooperation (APEC) (2010:3), explained that CBT may enhance social sustainability by empowering local communities to manage their own resources, providing meaningful employment and assisting with capacity building and cultural preservation. Environmental benefits include income generation for communities to actively protect their land from degradation and possible enhancement of conservation efforts to attract tourists especially with regard to ecotourism initiatives.

\section{RESEARCH METHODOLOGY}

The primary objective of the study was to determine the sustainability of financial investment in CBT projects in the Thabo Mofutsanyana District of the Free State Province. The secondary objective was to determine if the projects can sustain themselves after funding support has been terminated. The descriptive study used a self-administered questionnaire as a tool for gathering information that was distributed to the twenty-one (21) CBT projects within the Thabo Mofutsanya District. The sampling method used the formula by Stoker, which required that twenty (20) questionnaires be distributed to the population of twenty-one (21) CBT projects. A pilot study was undertaken on one successful and one unsuccessful CBT project to verify the questionnaire. After the data was collected, SPSS analysis was used as a statistical tool to prepare the data for analysis. 
The Thabo Mofutsanyana District is located in the Eastern Free State in South Africa. The area can be defined as rural and per-rural surrounded by several secondary cities such as Bethlehem and Ladybrand. Agriculture is the main economic activity is this region. A tourism enclave in Clarens has been established which has seen tourism emerging as a major economic contributor to the Eastern Free State. According to the Thabo Mofutsanyana Integrated Development Plan (IDP) (2012), the Thabo Mofutsanyana District Municipality was chosen since it includes the majority of CBT projects in the Free State Province. There are 21 CBT projects at different stages of development in this area, 11 of which are currently in progress.

These are the projects to which funds were allocated timeously and the owning agencies were identified without any hindrances from government departments. The remaining ten projects either have failed or were declared redundant for different reasons. The CBT projects in this area are categorised into accommodation establishments (hotels, guesthouses, lodges and rondavels), hiking trails, hospitality training centres, craft centres, tourism routes, communication centres, water sports and other water activities. Data collection was undertaken through self-completion questionnaires conducted between August and September 2014.

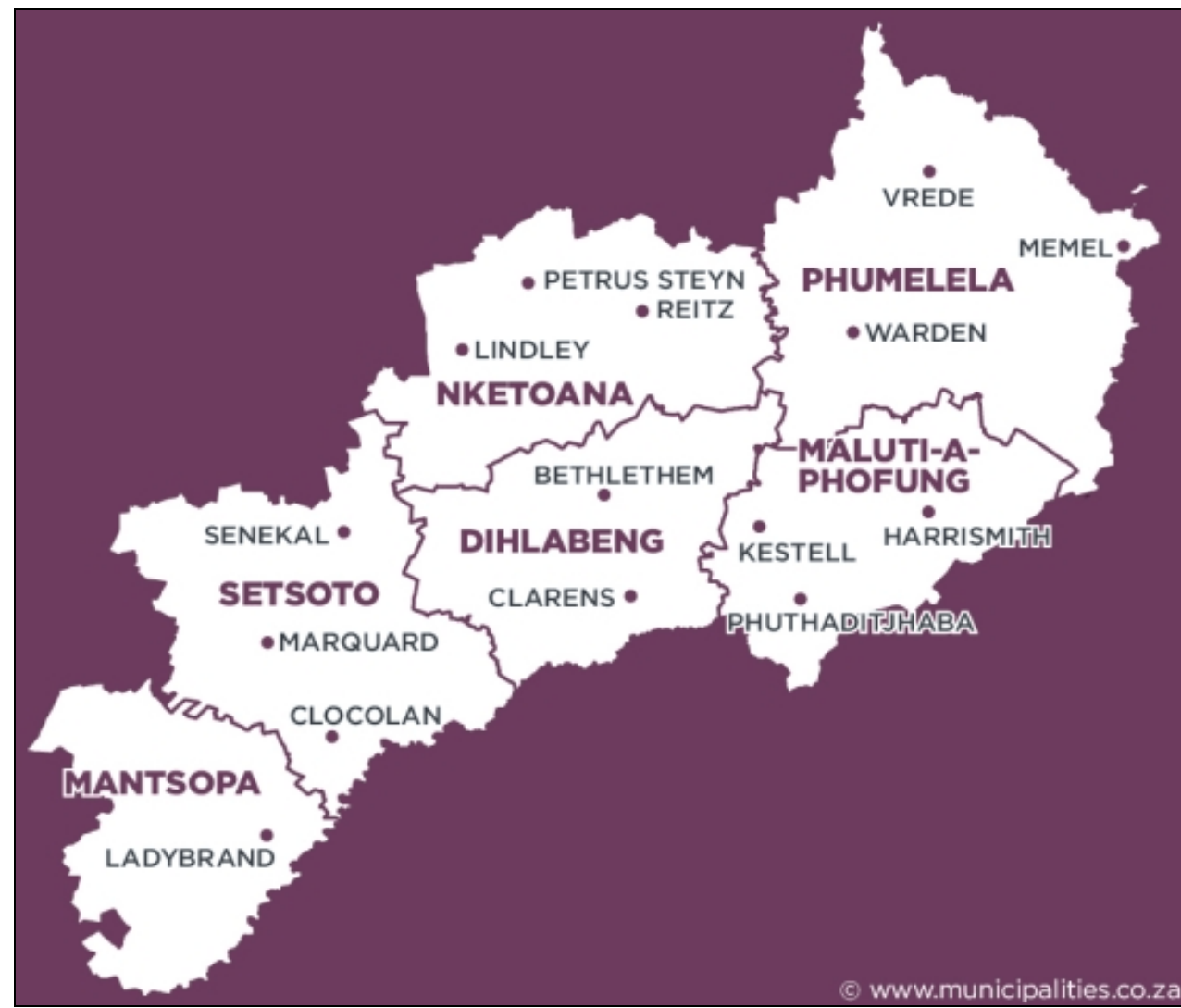

Figure 1. Map of Thabo Mofutsanyana geographical area (Source: municipalities.co.za, 2012)

\section{RESULTS AND DISCUSSION}

The purpose of the study was to determine the sustainability of financial investment in CBT projects in the Thabo Mofutsanyana District of the Free State 
Province. The total number of respondents (N-community representatives) was 252. It is vital to clarify the roles and responsibilities of both the community representatives and the government officials in CBT project development. It is also important that the roles and responsibilities of all role players in development should complement each other rather than contradict each other. The government officials also play a vital role and have responsibilities towards the development of the CBT projects. In the development of CBT projects, the role of government is to improve infrastructure and establish a policy for tourism activities and controls on land use.

The government officials are therefore entrusted with the facilitation and execution of the roles and responsibilities of the government in the development of tourism projects. $59 \%$ of the respondents are male and the median age of the group is 37 years (inter-quartile range (IQR): 30 to 45 years). $95 \%$ of the community representatives were involved in one project only; followed by $3 \%$ in two projects and $2 \%$ in four projects and none were involved in three projects.

With reference to the percentage of CBT projects that community representatives were involved, $95 \%$ of the community representatives were involved in one project only; followed by $3 \%$ in two projects and $2 \%$ in four projects and none were involved in three projects. It poses a risk in the sense that by far, the majority of them were only exposed to one project and they therefore lack a broad experience basis. With reference to the involvement of community representatives in the initial planning stage of the CBT projects, $52 \%$ of the community representatives were involved in the initial planning of the projects. Therefore, this implies that $48 \%$ of them did not have information on why the project was initiated and they were never part of the planning and decision making process. It poses a risk when it comes to decisions that shape the project's destiny. In terms of frequency of community involvement during the initiation of CBT projects, $52 \%$ of the respondents indicated that they were not aware of how often the community was involved during the initiation phase since they were not involved themselves. Only 23\% and $15 \%$ of the respondents respectively indicated that the community was always or often involved during the initiation of the CBT projects. For successful results in community development, it is always vital to involve communities at the initial planning stages because it assists in creating a sense of belonging and empowerment amongst the communities. According to Giampiccoli and Kalis (2012:174), the original concept of CBT must be seen as linking the concepts of sustainability, empowerment and self-reliance. This implies that the planning process was not as inclusive as possible.

This caused people to lose interest in the success and sustainability of the project. Only a third of the community representatives (34\%) indicated that they were always involved in the monitoring of progress of the CBT projects and actively monitored it with the government officials. With regard to the community needs that were positively impacted by the CBT projects, the development of the CBT projects, the needs of the respondents have been satisfied through direct employment and/or self-employment (67\%), followed by $22 \%$ who reported that they have been equipped with skills transfer, training and development. Therefore, this explains that some of the projects have the potential of being sustainable if the people affected are continually empowered so that their socio-economic status becomes sustained and a sense of belonging and ownership of the projects are ensured. $87 \%$ of the respondents indicated that the community benefited from the projects and $13 \%$ did not agree. The CBT projects have positively benefited the local community since the respondents have been capacitated with relevant skills (32\%), they have secure jobs (25\%) and have also experienced an improvement in their quality of life (23\%). The respondents also indicated that they have generally benefitted socially and culturally which fulfils the guiding principles of 
CBT development of securing the social, cultural, environmental and economic status of the population affected by the development. With regard to government's contribution to the CBT projects development, training and skills transfer is vital for CBT projects to be successful. Community representatives need to be equipped with relevant skills in order to perform their duties at an acceptable standard.

From the study, $84 \%$ of the respondents agreed that the government equipped them with relevant skills to perform their duties while $16 \%$ disagreed. It is clear that $59 \%$ of the community representatives were trained in entrepreneurial skills. This is followed by tourist guiding at $53 \%$, arts and crafts at $51 \%$, housekeeping at $41 \%$, water sports at 29\%, leadership and management at $27 \%$, administration at $20 \%$, environmental issues at $16 \%$, guest house management at $14 \%$, marketing at $8 \%$, accounting at $4 \%$, and oral history, traditional healing and cultural issues at $2 \%$ each. The training programmes that achieved a score above $50 \%$ indicate that there have been properly empowerment and sustainability for the developments. Therefore, this suggests that there will be an increased commitment and capability in the projects' development and systematic on-the-job learning will be provided for those community members that did not get training. As for those programmes lower than 50\%, they indicate that there might be lack of ability to manage and operate the projects, which suggests a need for intensified provision of systematic on-the-job learning.

Other than offering training and development to the community members, which is supported by the Tourism White Paper of South Africa, the government introduced four benefit- sharing mechanisms to the community. The principal idea of the concept is to share the benefits resulting from the development of the natural resources in order to satisfy the needs of the concerned population. According to Oula (2006:57-58), benefit sharing with the affected local population refers to a commitment to channel some of the returns generated by the operation of a project back to the community where natural resources are exploited and infrastructure projects are developed. The relevance of this concept is that it has been recognised that modern compensation policies for projects that affected people should involve not only basic in-kind and cash compensation for lost assets and lost access to resources, but also measures that aim to restore and improve the livelihoods of the affected populations in the long-term (Prachvuthy, 2006:26-40). Below are some examples of benefit sharing schemes:

- Community Trust Fund: a fund acquired from inheritances income from which is to be used for the general betterment of the inhabitants of a community (Duruigbo, 2004:121).

- Share of profits: refers to various incentive plans introduced by businesses that provide direct or indirect payments to employees that depend on the company's profitability in addition to employees' regular salaries and bonuses. In publicly traded companies, these plans typically amount to allocation of shares to employees.

The profit sharing plans are based on predetermined economic sharing rules that define the split of gains between the company as a principal and the employee as an agent (Kate \& Laird, 2002:4-5).

- Member of Board of Trustees: an appointed or elective board that supervises the affairs of a public or private organisation. They are responsible for guiding and assessing the effective implementation of the project's mission from the initial planning of the projects. That is, they are responsible for defining and monitoring the short and long-term goals of the projects, setting policies in accordance with the project's mission, support the management in the day-to-day operation but are not involved in management and administration. They are also responsible for approving the yearly budget (McKinnon, 1973:7). 
- Revenue sharing: revenue sharing with the local or regional authorities can be arranged through royalties tied to the output of the project or through entrance fee charges. The amounts either are settled through negotiations between the local or regional authorities and the promoter or operator, are defined in the legislation (Cachon \& Lariviere, 2005:30-35).

The respondents were asked whether the government has addressed community benefit sharing mechanisms. The majority (80\%) agreed, while $12 \%$ did not agree and $8 \%$ did not know about the mechanisms. The respondents motivated their responses differently in the sense that $56 \%$ of respondents who indicated that community trust funds have been set up explained that the government and private investors have assured them that employment opportunities will be provided and direct revenue to the community trust fund will be guaranteed. This implies that if successful, there will always be income for the community over the long-term in case they want to venture into other businesses as a community, which means that the fund will be their investment or capital needed for such ventures. According to the study, $21 \%$ of the respondents indicated that there has been a collaborative agreement with the private sector, local government and the community that there will be a certain percentage of profits that will be shared amongst the community members involved in the development. This suggests that all stakeholders will receive dividends, which will motivate and compensate employees who are community members.

The community will be entitled to profits and other payments, which assists in positively influencing work effectiveness, productivity, good quality work and service, and lowering high costs. Another benefit sharing mechanism that some respondents agreed to be discussed with them is the establishment of a Board of Trustees. Only $4 \%$ of the respondents mentioned that there is a certain percentage of profits that is allocated to the community under the guardianship of the elected Board of Trustees on behalf of the community. The low percentage indicates that the introduction of this mechanism was inadequately executed or the respondents did not understand the mechanism. Lastly, the majority of respondents (80\%) confirmed that revenue sharing mechanisms were discussed which means that a certain percentage of the daily takings (entrance fees and sales) will go directly to the service providers and affected communities. These responses indicate that all stakeholders agreed in ensuring that communities enjoy the benefits of the projects to encourage a sense of ownership to the projects, hence dedicate themselves to the projects' success and sustainability. In the management of project finances, the majority (77\%) of the respondents indicated that the project finances were well managed, while $21 \%$ did not agree. The majority of respondents indicated that the reasons for failure of CBT are mainly in the area of mismanagement of funds (69\%). This is followed by the exclusion of other stakeholders (33\%), lack of empowerment, knowledge, skills and training (25\%). The lack of planning, research and consultation is at (12\%). The imposing projects on communities and lack of communication amongst stakeholders is at (10\%). Conflict amongst communities and rejection of projects by communities is at (10\%). Corruption, laziness and red tape by government officials are at (5\%). Moreover, bad marketing (3\%) and neglecting the importance of culture and environment are at (3\%).

All these reasons are crucial for the development and sustainability of any community project. In this regard, it is obvious that project-planning processes were not carried out well or the stakeholders ignored the details on the characteristics and principles of CBT projects, or the guidelines for the development of CBT projects were ignored. Stakeholders must follow the correct procedures in developing and implementing CBT projects. In review of the respondents' responses, 100\% reported that the financial support for the development of CBT projects comes from the National Department of Economic 
Development, Small Business Enterprise, and Tourism and Environmental Affairs (DETEA). Other support comes in the form of exchange of skills, research and consultation, investment and management and marketing from different governmental and nongovernmental entities. The respondents further indicated that the municipality assists in coordinating (100\%) all activities with relevant bodies responsible for the CBT project development. The respondents (53\%) suggested that the communities needed to be empowered in order for the CBT projects to be sustainable in the Thabo Mofutsanyana Municipality. All stakeholders must work together for the success of the projects (29\%). There is a need to practice proper ways of developing a CBT project (8\%). Employment of a Public Private Partnership strategy (PPP) has to be engaged in (4\%). Open communication lines amongst the stakeholders must be created (4\%). All these suggestions are encompassed in the principles and guidelines of a successful and sustainable CBT project.

\section{CONCLUSIONS AND RECOMMENDATIONS}

Achieving sustainable CBT is a continuous process that requires constant monitoring and evaluation of impacts and introduction of the necessary pre-emptive and/or counteractive measures. Implementation of CBT initiatives plays an important role in the success or failure of the initiative, starting from initial planning to monitoring and evaluation processes. According to the Rural Tourism Strategy (2012:8), rural tourism has been insufficiently funded and resourced. The reason for this is that funding comes only from the National Department of Tourism (NDT). It is imperative that the government involves other donor agencies in funding CBT projects because it is the nature of CBT projects to be fully dependent on donor funding. This will assist in increasing community benefits from conservation and sustainable management of natural resources within the project areas. Involving the donor agencies also assists in extensive marketing and increases investment opportunities, but it is always a challenge for donors to support CBT projects because of their nature of creating low profit margins and taking a long time to generate profits. This does not mean that government should not forge investment opportunities from local, regional and international donors interested in or accustomed to working with rural development or even CBT projects. The following recommendations will not only be applicable to the CBT projects in the study area but can also be adopted by all envisaged CBT projects in rural areas:

- The government working with the private sector must establish sustainable CBT projects that will have a lasting impact on the livelihoods of the community.

- The community, and not the community elites, must be involved from the conceptualisation to the delivery of the CBT.

- Partnerships with tourism intermediaries must be established when the project is conceptualised.

- CBT need government support in terms of infrastructure provision such as roads, signage and lighting, which would improve the experience to and from the CBT project.

- CBT project must be hallmarks of good governance and management.

- CBT must ensure that the public are given access to the project, so that they can learn about the importance of tourism as an economic sector. This will ensure that the public becomes tourism friendly, and improve the experience of the tourists that visit the locality.

- CBT projects will only succeed if successful integrated marketing is undertaken to ensure that the marketing outlays are successful in cultivating sustainable tourism demand.

- Viability studies and market access studies must be undertaken to ensure that CBT projects attract tourists so that they can become fully functional and operational. 
The governments interference in the decision-making process most of the time undermines community empowerment. Furthermore, the findings of the study also discovered that local government is mandated with overseeing the utilisation of government funding, of which according to the respondents, the local government officials negatively manipulate the utilisation of funding. The involvement of communities in the development of CBTs gives them power to make decisions on issues that involve their assets including their communal resources, living standards and their future. According to Henama \& Sifolo (2017), the tourism industry is supposed to increase the standard of living of locals and the quality-of-life of the host community. CBT becomes a means to an end in trying to ensure that tourism benefits the local community, ensuring that the developmental benefits of tourism are shared.

\section{REFERENCES}

Acha-Anyi, P.N., Henama, U.S., \& Sifolo, P.P.S. (2016). The low cost carrier bandwagon: Lessons for Skywise Airline. African Journal of Hospitality, Tourism and Leisure, 5 (2): 1-23.

Anstand, M. (2006). Community-based tourism and socio-culture aspects relating to tourism - A Case Study of a Swedish student excursion to Babati (Tanzania). Retrieved from: http://www.divaportal.org/smash/get/diva2:16436/FULLTEXTo1.pdf. [Accessed 13 May 2013].

Aref, F. \& Redzuan, M.B. (2009). Community Capacity Building for Tourism Development. Journal of human ecology, 27(1):21-25.

Ashley, C., De Koch, M., \& Spenceley, A. (2009). Tourism and local development: an introductory guide. Tourism-led poverty reduction programme. Retrieved from: http://www.intracen.org/uploaded Files/intracenorg/Content/Exporters/Sectoral_Information/Service_Exports/Tourism/TPRP\%20Core \%20Module.pdf. [Accessed 15 March 2014].

Asian Pacific Economic Cooperation (2010). APEC CEO Summit 2010 Yokohama. Japan.

Beeton, S. (2006). Community development through tourism. Australia: Landlinks Press.

Cachon, G.P. \& Lariviere, M.A. (2005). Supply chain coordination with revenue-sharing contracts: strengths and limitations. Management science, 51(1):30-44.

Casimiro, R., \& Spenceley, A. (2012). Tourism concessions in protected areas in

Mozambique: Analysis of tourism concessions models in protected areas in Mozambique. Mozambique. DAI and Nathan Associates.

Dimoska, T. (2006). Tourism and Least Developed Countries - A Sustainable Opportunity to Reduce Poverty. Economics and Organisation, 5(2):1-12.

Duruigbo, E. (2004). Managing Oil Revenues for Socio-Economic Development in Nigeria: The Case for Community-Based Trust Funds. Thesis (Masters). California: Stanford University.

Engstrom, D. \& Leffler, R. (2012) Perceptions of climate change at ski resorts in midsouth of Sweden. Thesis (BTech). Sweden: Dalarna University.

Essex, S.J., Gilg, A.W., Yarwood, R.B., Smithers, J. \& Wislon, R. (2005). Rural change and sustainability: Agriculture, the environment and communities. United Kingdom: CABI Publishing.

Giampiccoli, A. \& Kalis, J.H. (2012).Community-based tourism and local culture: the case of amaMpondo. PASOS Revista de Turismo y Patrimonio Cultural, 10(1): 173-188.

Goodwin, H. \& Santilli, R. (2009). Community-based tourism: a success? Retrieved from: http://www.haroldgoodwin.info/uploads/cbtasuccesspubpdf.pdf. [Accessed 15 Jan. 2013].

Gopaul, M. (2006). The significance of rural areas in South Africa for tourism development through community participation with special reference to Umgababa, a rural area located in the province of KwaZulu Natal. Thesis (Masters). South Africa: University of South Africa. Retrieved from: http://www.uir.unisa.ac.za /bitstream/handle/10500/2159disseratation.pdf?sequence=1, [Accessed 20 Jan. 2012].

Hall, C., Lindo, P., Vanderschaeghe, M., \& Zpata, M.J. (2011). Can community-based tourism contribute to development and poverty alleviation? Lessons from Nicaragua. Current Issues in Tourism, 14(8), 725-749.

Hashimoto, A. \& Telfer, D.J. (2006). Selling Canadian tourism: Branding the global and the regional product. $8(1), 42-45$.

Henama, U.S. (2013). Attracting Indian Outbound Tourists to South Africa: A BRICS Perspective. India Quarterly, 69 (3): 229-247.

Henama, U.S. (2014). The demise of 1Time airline and the reaction of various interest groups. African Journal of Hospitality, Tourism and Leisure, 3 (2): 1-12.

Henama, U.S. \& Sifolo, P.P.S. (2017). Tourism migration in South Africa: Current Dynamics, Immediate Challenges and Future Prospects. International Journal of Innovation in the Digital Economy, 8 (1): 47-60. 
Henama, U.S., Mangope, D., \& Strydom, A.J. \& (2017). Economic sustainability guidelines for a communitybased tourism project: The case of Thabo Mofutsanyana, Free State Province. African Journal of Hospitality, Tourism and Leisure, 6 (3): 1-17.

Hockett, E. (2009). Socio-cultural sustainability of rural community-based tourism: Case Study of Local Participation in Fair Trade Coffee Trail, Nicaragua 2. Thesis (PhD). Rovaniemi. Lapland University. Retrieved from: http://www.academia.edu/2357891/Sociocultural_Sustainability_of_Rural_Community based_Tourism_Case_study_of_local_participation_in_Fair_Trade_Coffee_Trail_Nicaragua.

[Accessed 20 March, 2014].

Honey, M. (2009). Community conservation and early ecotourism: experiments in Kenya. Environment: Science and Policy for Sustainable Development, 51(1):46-57.

Kate, K. \& Laird, S.A. (2002). The commercial use of biodiversity: access to genetic resources and benefitsharing. United Kingdom. Earthscan Publications.

Kauppila, P., Saarinen, J. \& Leinonen, R. (2009). Sustainable tourism planning and regional development in Peripheries: A nomadic view. Scandinavian Journal of Hospitality and Tourism. 9:4, 424-425.

Koster, R. (2010). Rural tourism in Canada. Journal of Rural and Community Development, 5(1):4-5.

Matarrita-Cascantea, D., Brennanb, M.A. \& Luloff, A. E. (2010). Community agency and sustainable tourism development: the case of La Fortuna, Costa Rica. Journal of sustainable tourism, 18(6): 9, July.

McKinnon, R.I. (1973). Money and capital in economic development. Washington, DC: Brookings Institution Press.

Mearns, K.F. (2011). Community-based tourism and peace parks benefit local communities through conservation in Southern Africa. Bloemfontein: University of South Africa.

Mearns, K.F. (2012). Lessons from the application of sustainability indicators to community-based ecotourism ventures in Southern Africa. African Journal of Business Management, 6(26): 7851-7860.

Ndlovu, N. \& Rogerson, C.M. (2003). Rural local economic development through community-based tourism: the Mehloding hiking and horse trail, Eastern Cape. South Africa. Africa Sight, (33)1:124-125.

Ndlovu, N. \& Rogerson, C.M. (2004). The local economic impacts of rural community-based tourism in the Eastern Cape. Tourism and development issues in contemporary South Africa. Pretoria: Africa Institute of South Africa.

Oula, T. (2006). Financial Benefits and Income Distribution of Community-Based Tourism: Nammat Kao and Nammat Mai, Lao PDR. Journal of GMS Development Studies, 3(1): 57-58.

Prachvuthy, M. (2006). Tourism, Poverty, and Income Distribution: Chambok Community-based Ecotourism Development, Kirirom National Park, Kompong Speu Province, Cambodia. Journal of GMS Development Studies, 3(1): 25 -40.

Rogerson, C.M. (2018). Informal sector city tourism: Cross-border shoppers in Johannesburg. GeoJournal of Tourism and Geosites, 22 (2): 381-392.

Ruhiu, J.M. (2007). Funding Community-based tourism: Capital for Investing in Community-based tourism (CBT) - Grants Vs Loans: 2, 22nd -24th Oct. Available: Environment Conservation Facility (CEF).

Saarinen, J. (2006). Aspects of Tourism. Nordic Tourism: Issues and Cases. New York. Routledge.

Sharpley, R., \& Telfer, D.J. (2008). Tourism and Development in the developing world. United Kingdom. Routledge. 124

Tichaawa, T.M. \& Makoni, L. (2018). Sociodemographic influences on resident's perceptions of tourism developments in Zimbabwe. GeoJournal of Tourism and Geosites, 22 (2): 432-446.

Tlabela, K., \& Viljoen, J. (2007). Rural tourism development in South Africa: Trends and challenges. Cape Town. HSRC Press.

Wehkamp, A. (2007). A Toolkit for Monitoring and Managing Community-Based Tourism. Vietnam: SNV and Griffith University

*** Municipalities. (2012). Map of Thabo Mofutsanana District Municipality. Retrieved from: https://www.municipalities.co.za. [ Accessed 10 October 2018].

*** South Africa. (1996). National Department of Economic development, Tourism and Environmental Affairs. White Paper on the development and promotion of tourism in South Africa. Pretoria: Government Printer.

*** South Africa. (2002). National Department of Economic development, Tourism and Environmental Affairs. Responsible Tourism Manual for South Africa. Pretoria: Government Printer.

*** South Africa. Local Government. (2011). Thabo Mofutsanyana District Municipality: An integrated development plan. Bloemfontein: Government Printer.

*** South Africa. Local Government. (2012). Thabo Mofutsanyana District Municipality: An integrated development plan. Bloemfontein: Government Printer.

*** Tango International. (2009). Knowledge for development effectiveness: Sustainability of rural development projects. Asia. IFAD.

Submitted:

29.08.2018
Revised:

03.12.2018
Accepted and published online 06.12.2018 